\title{
DECARBONISING THE SWEDISH ROAD TRANSPORT SECTOR
}

\author{
ANN-CHARLOTTE MELLQUIST, JAMIE PIRIE, ALISTAIR SMITH, JON STENNING, \\ EMANUELA VANACORE \& MATS WILLIANDER \\ Research Institutes of Sweden, RISE Viktoria, Sweden \& Cambridge Econometrics, UK.
}

\begin{abstract}
Road transport contributes to around one-fifth of the EU's total $\mathrm{CO}_{2}$ emissions and is the only major sector in the EU where greenhouse gas emissions are still rising. Swedish road transport causes $30 \%$ of all emissions. Addressing transport emissions is therefore crucial for meeting the Paris Agreement commitments on climate change.

The Swedish government aims to have a fossil-independent vehicle fleet by 2050; moreover, an emissions reduction target for the road transport sector of $80 \%$ (compared to 2010) by 2030 has been suggested. The government-initiated investigation 'Fossilfrihet på väg' sets out potential pathways, but a knowledge gap currently remains in regard to which path would be the most beneficial or least burdensome in terms of macroeconomic effects while still decarbonising the road transport sector.

This paper contributes to fill that knowledge gap by applying a vehicle stock modelling framework and a demand-driven global econometric model (E3ME) and by evaluating different technology pathways for Sweden to meet the 2030 and 2050 government targets. The stock model has been adjusted to be consistent with 'Fossilfrihet på väg' and uses technology deployment and cost estimates to model the Swedish vehicle stock emissions in three technology-driven scenarios.

The analysis shows that decarbonisation of transport can have positive impacts upon the Swedish economy, primarily through the replacement of imported fossil fuels with domestically produced electricity and biomass, while a further stimulus is provided by the construction of infrastructure to support electric vehicle recharging and fuel cell refuelling. Through quick action to encourage the deployment of new technologies and powertrains into the vehicle stock, plus policies aimed at promoting the domestic production of sustainable biomass, Sweden can maximise the potential gains from the decarbonisation process.
\end{abstract}

Keywords: macroeconomic impacts, road transport, technology pathways, vehicle emissions.

\section{INTRODUCTION}

Sweden is one of the signatory countries to the Paris Agreement, aimed at keeping the global temperature rise well below 2 degrees Celsius compared to pre-industrial levels. Road transport contributes around one-fifth to the EU's total emissions of $\mathrm{CO}_{2}$, and is the only major sector in the EU where greenhouse gas emissions are still rising. Addressing transport emissions is therefore an important part of meeting the Paris Agreement commitments on Climate Change. Since 1970s Sweden has undergone a process of decarbonisation of the economy through the installation of district heating, waste incineration plants for heat and electricity production and nuclear hydropower [1]; as these 'low hanging fruit' measures are increasingly taken up, future carbon emission reductions as required under Sweden's Nationally Determined Contributions (NDCs) under the Paris Agreement will become increasingly dependent upon the ability to decarbonise the hitherto relatively 'untouched' road transport sector.

Currently, road transport is responsible for $80 \%$ of Sweden's annual oil consumption, compared to a global average of around 50\% [2]. The Swedish government aims to have a fossil fuel-independent vehicle fleet by 2050 and a target of a $70 \%$ reduction in emissions in 2030 (compared to 2010) has been recommended [3]. It has been suggested that the $70 \%$ reduction in emissions from the transport sector as a whole could be met through an $80 \%$ reduction in 
the road transport sector and smaller reductions in the maritime and aviation sectors [3]. The governmental-initiated investigation 'Fossilfrihet på väg' [4] sets out potential pathways for this but does not compare their macroeconomic effects for Sweden. A number of studies have been carried out to assess the macroeconomic impact of decarbonising passenger cars, both at a European and Member State level [5-7]. Very few macroeconomic impact studies of $\mathrm{CO}_{2}$ emissions reductions have been undertaken for Sweden [1] and none has focused on the Swedish road transport sector. There is therefore limited knowledge as to which path to decarbonising the road transport sector would be the most beneficial or least burdensome for Sweden in terms of macroeconomic effects.

This paper explores potential pathways to meeting the Swedish emissions target. We apply a vehicle stock modelling framework to assess the role that different deployment rates of fuel efficiency technologies and advanced powertrains can play in allowing the vehicle stock to meet this target, and the extent to which biofuel blending must be used to meet the shortfall so that all technology deployments ultimately meet the 2030 target. We then apply a macroeconometric simulation model (E3ME) to assess the potential economic impacts of different technology pathways in terms of GDP, employment, consumer expenditure and investment plus imports.

\section{APPROACH}

The decarbonisation of road transport is modelled through a Vehicle Stock Model (VSM), which calculates the outcomes of technology-led scenarios in terms of energy demand by fuel and consumer expenditure on road transport and fuels, plus investment in infrastructure. These are then fed into the E3ME model to provide a detailed analysis of the effects of different technology pathways that meet the Swedish Government's road transport carbon emissions target on the Swedish economy.

E3ME is a demand-driven global macro-econometric simulation model covering 59 global regions with detailed sectoral disaggregation [8]. It projects forwards annually up to 2050. It has an integrated treatment of the economy, energy system, emissions and material demand. The model has been applied to assessing the macroeconomic impacts of decarbonising road transport in a number of studies across Europe, including Fuelling Europe's Future [5] and national studies in the UK [6] and France [7].

The motor vehicle fleet, with an average vehicle life span of well over 10 years, can take time to see changes in the characteristics of new vehicles feed through to the whole fleet. To capture this, we use a vehicle stock model to develop a representation of the current Swedish vehicle fleet and allow us to model scenarios for the deployment of new vehicle powertrains and efficiency improvement technologies.

The vehicle stock model works on basis of modelling annual cohorts of vehicles as they enter the stock (as new vehicle sales) and then model changes in characteristics (such as average distance driven) as they age, until they retire according to a survival rate curve, with a declining chance of survival as vehicles get older. This allows us to accurately model the propagation of new technologies in vehicles and the deployment of alternative powertrains and see how assumptions on deployments in sales over time translate into penetration across the vehicle stock.

We can then observe the overall impact on the characteristics of the vehicle stock to feed into the macroeconomic results in E3ME. The main results that feed into the results are fuel consumption by fuel type, average price of motor vehicles and investment in infrastructure to support alternative powertrains. 


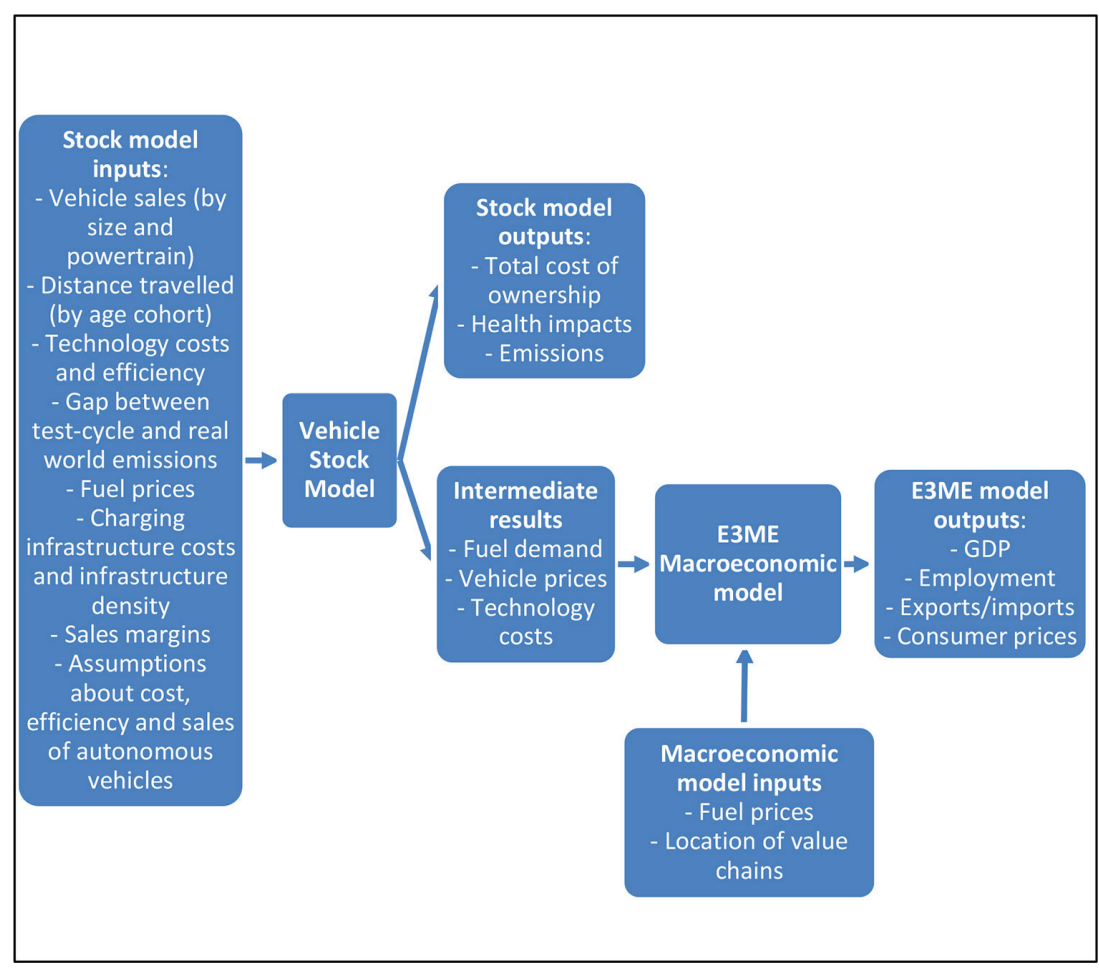

Figure 1: Key steps in the modelling framework.

The VSM is calibrated through the use of extended historical data, ensuring that the model successfully replicates historical vehicle stock estimates. Assumptions on the future deployment of fuel efficiency technologies and advanced powertrains are then input to develop the different scenarios; building upon a reference scenario which assumes that the Swedish new vehicle sales meet European Commission targets for carbon emissions in 2021 (of an average of $95 \mathrm{~g}$ of $\mathrm{CO}_{2}$ per kilometres) [9]. In total, three alternative scenarios have been implemented in the VSM and the results fed into E3ME.

E3ME is a detailed European and Global Economic, Energy and Environment (E3) model where relationships are estimated empirically. The structure of E3ME is based on the system of national accounts, as defined by ESA95 [10], with further linkages to materials, energy and environmental emissions. The labour market is also covered in detail, with estimated sets of equations for labour demand, supply, wages and working hours. International trade is modelled at bilateral sector level. In total there are 33 sets of econometrically estimated equations, also including the components of GDP (consumption, investment, and international trade), prices, energy and material demands. Each equation set is disaggregated by country and by sector.

E3ME's historical database covers the period 1970-2014 and the model projects forward annually to 2050. The main data sources are Eurostat, United Nations, OECD's Stan database, World Input-Output database (WIOD) and the IEA, supplemented by national sources. Gaps in the data are estimated using customised software algorithms. 
The economy module provides measures of economic activity and general price levels to the energy module; the energy module provides measures of emissions of the main air pollutants to the environment module, which in turn can give measures of damage to health and buildings. The energy module provides detailed price levels for energy carriers distinguished in the economy module and the overall price of energy as well as energy use in the economy.

\section{SCENARIO DESIGN}

The three scenarios have been designed to showcase different levels of policy intervention; assuming that the deployment of fuel efficiency technologies and advanced powertrains will be driven by supply-side policy, rather than manufacturers, the scenarios demonstrate the need for increasing policy ambition, in encouraging the deployment of ever more technology and larger shares of advanced powertrains, as well as increased use of biofuels. All of them meet the government-initiated emissions target of $80 \%$ reduction.

In each case, the technology and powertrain deployment was introduced first, based upon previous scenario analysis carried out by the authors and their own views as to what is viable in Sweden over the time period considered; to ensure that the 2030 emissions target was met in all cases (except the reference), drop-in biofuels are added (the required percentage of biofuel required in each case was calculated by the authors through a trial-and-error process).

\subsection{CPI}

The CPI (Current Policy Initiatives) is the baseline used in this analysis. It is a single pathway developed by the authors to deliver implemented government policy; in the case of passenger cars, this means that the emissions from the average new car in 2021 are $95 \mathrm{~g} / \mathrm{km}$. For buses and heavy-duty vehicles, where the European Commission currently has no confirmed emissions targets, there is no change in average emissions levels from today (and therefore no deployment of fuel efficiency technologies or advanced powertrains).

Given the short period of time that is available to meet the 2021 emissions targets, these are primarily met by the deployment of several fuel efficiency technologies in passenger cars and vans, although there is a slight increase in the deployment of plug-in hybrids (PHEVs, for both cars and vans) and battery electric vehicles (BEVs) by 2021, to 2\% and 1\%, respectively.

\section{$3.2 \mathrm{BIO}$}

This scenario shows no substantial change in the powertrain mix of new sales of passenger cars from the current state of play; internal combustion engines (ICEs) are $94.5 \%$ of all sales in 2030, with the remainder consisting of hybrids (HEVs, 2.5\%), plug-in hybrids (PHEVs, $2.0 \%$ ) and battery electric vehicles (BEVs, 1.0\%). However, the deployment of new technology improves the fuel efficiency, and therefore, the emissions intensity, of these vehicles as compared to their current equivalents. Similar trends are observed in buses and HGVs; for buses and vans, ICEs are 94.5\%, with the remainder HEVs, PHEVs and BEVs, while in HGVs are almost all ICEs (the only exception being $0.2 \%$ of sales of the smallest category of HGVs, which are BEVs).

Across all vehicle types, the primary policy, which reduces emissions, is the use of drop-in biofuels. In order to reach the 2030 carbon emissions target, $43 \mathrm{TWh}$ of biofuel is required 
(with the biofuel component reaching 70\% for both petrol and diesel), around four times as much as it is estimated can be produced on a sustainable basis within Sweden; the remainder is imported, in this scenario.

\subsection{ELEC}

In this scenario, the technology deployment used in the BIO scenario is taken as a starting point, and augmented by an ambitious electrification of the vehicle fleet. As such, there is a noticeable shift in the powertrain mix of new sales of cars, vans and (to a more limited extent) HGVs over the period to 2030. Cars and buses rapidly switch to sales of BEVs (which are $70 \%$ of sales for both by 2030), as well as increased sale shares of PHEVs (30\% and 10\%). For freight vehicles, there is a distinction between vans and light HGVs, where the shift is to a mix of BEVs and PHEVs, medium HGVs, which see an increasing roll out of PHEVs, and heavy HGVs, where sales remain exclusively focussed on ICE powertrains.

To meet the remaining gap to the 2030 target, drop-in biofuels are introduced and fuel mixes reach $40 \%$ and $60 \%$ for petrol and diesel respectively in 2030 . The 24 TWh of biofuel required is around twice the amount that can be sustainably produced domestically, with the remainder needing to be imported.

\subsection{FCV}

In this scenario, in addition to the technologies and powertrains deployed in the ELEC scenario, additional powertrain shifts are deployed, reducing the percentage of new sales attributed to ICEs, PHEVs and BEVs at the expensive of a rapid expansion in the sales of fuel cell electric vehicles (FCEVs). Amongst passenger cars and buses, while some HEVs and PHEVs remain, all BEVs are replaced by FCEVs. Across HGVs, the impact is even larger; while in the earlier scenarios sales remained dominated by ICEs, the development of fuel cell infrastructure allows large proportions of the HGV fleet to shift to fuel cells.

Despite this extreme technology and powertrain deployment, the carbon emissions target was still not reached. As a result, drop-in biofuels were again deployed at $40 \%$ for petrol and $60 \%$ for diesel. The 22 TWh biofuels required in this scenario will also require a portion of imports of biofuels, as in the ELEC scenario.

\section{ANALYSIS}

The four scenarios all have different impacts upon the Swedish economy, as captured in the E3ME model. In the analysis that follows, the three alternative technology and powertrain deployments are compared to the CPI scenario, which forms the baseline for this analysis (based, as it is, upon announced policy).

The economic impacts of the decarbonisation of transport are likely to be felt in a number of different ways. Changes in the purchase prices of vehicles and fuels will have impact upon consumer spending, in terms of how much is allocated towards buying and running a vehicle, and how much is available for spending on other items; increased investment, required to provide the required charging and refuelling infrastructure, will have positive short-term economic impacts (although within the modelling, all investment is ultimately 'paid back'); and changes in fuel demand will impact upon imports of fossil (and potentially other) fuels. These effects are all considered individually below; note that the focus is primarily on the period to 2030, as it is this year in which the Swedish emissions target has to be met; however, the analysis continues out to 2050 to measure the impact of the technology deployment 
(some of which only starts to enter the stock just before 2030) as it permeates through the vehicle stock.

\subsection{Output}

In the modelling analysis, all the scenarios show a positive economic impact in terms of GDP, as compared to the baseline. The largest impact in 2030 is in the ELEC scenario $(0.4 \%$ higher than baseline in 2030), followed by FCV (0.3\%) and BIO (0.1\%), although by 2050 the FCV scenario has the largest difference from baseline, primarily as a result of the additional investment required to provide fuel cell recharging stations. The ELEC scenario has a higher deployment of advanced powertrains by 2030 compared to FCV, reflecting the fact that the time horizon for feasible mass deployment is further away for fuel cell vehicles.

The differential impacts are driven by three separate effects;

- A shift in consumer expenditure patterns, driven by changes in the costs associated with purchasing and operating a motor vehicle;

- An increase in investment, which is required to fund the infrastructure (for both electricity and hydrogen) required to refuel a fleet of advanced powertrain vehicles;

- A change in imports, resulting from a decrease in demand for imported fossil fuel, and their replacement with domestically produced biofuels, electricity or hydrogen.

These are explored in more detail below. The key sectoral impacts in terms of output are: an increase in outputs from consumer services, as a result of increased consumer expenditure in these sectors; a boost to manufacturing and construction, from the additional investment stimulus; and higher output in domestic energy production and supply from the replacement of imported fuels with domestic energy. In addition, the multiplier effects result in a small additional increase across the economy as a whole.

\subsection{Employment}

The positive GDP impacts outlined above also translate to increased employment in the Swedish economy. The percentage increase above the baseline in employment in each

Table 1: GDP expenditure at market prices. Relative difference compared to baseline.

\begin{tabular}{lcc}
\hline Scenario & $\mathbf{2 0 3 0}$ & $\mathbf{2 0 5 0}$ \\
\hline BIO & $0.1 \%$ & $0.3 \%$ \\
ELEC & $0.4 \%$ & $0.7 \%$ \\
FCV & $0.3 \%$ & $0.9 \%$ \\
\hline
\end{tabular}

Table 2: Industry employment. Relative difference compared to baseline.

\begin{tabular}{llc}
\hline Scenario & $\mathbf{2 0 3 0}$ & $\mathbf{2 0 5 0}$ \\
\hline BIO & $0.1 \%$ & $0.3 \%$ \\
ELEC & $0.5 \%$ & $0.8 \%$ \\
FCV & $0.6 \%$ & $1.0 \%$ \\
\hline
\end{tabular}


scenario is larger than the increase in GDP, as the jobs being created have below-average productivity (for example, the largest sectoral employment increase, in absolute terms, is in retail, where productivity levels are relatively low).

The largest difference from baseline is in the FCV scenario (0.6\% in 2030), with smaller positive impacts in ELEC (0.6\%) and BIO (0.1\%). The sectoral distribution of the increases is broadly similar, although percentage increases (relative to those seen in other sectors) are higher in consumer services, due to the relatively low productivity levels of these jobs (meaning that more jobs are required to deliver the increase in output driven by increased consumer expenditure).

\subsection{Consumer expenditure}

The deployment of fuel-efficient technologies, including advanced powertrains (batteries and fuel cells) increase the purchase price of vehicles, but reduce the running costs; within the modelling, this is only in terms of reduced fuel costs, but there is some evidence that EVs have lower maintenance costs, due to the simplified nature of the powertrain compared to an internal combustion engine. As such, many of these technologies reduce the total cost of ownership (TCO) of vehicles. In addition, as technologies are more widely deployed, the cost of these technologies comes down, meaning that some technologies which may initially cause the TCO to increase can subsequently have the opposite effect, while technologies which start out reducing TCO will do so to an increasing extent as deployment rates increase. This decrease in TCO means that households need to devote less expenditure to motor vehicles and fuel, and can re-allocate the saved expenditure to other categories (including a rebound effect of more use of vehicles).

As a result, the primary impacts on consumer expenditure are a decrease in expenditure on motor vehicles and manufactured fuels, replaced by increased expenditure on electricity (for recharging of PHEVs/BEVs) and a smaller increase in expenditure across all other categories. The net increase in consumer expenditure in the scenarios comes primarily from the multiplier effects, chiefly the downstream effects of the additional investment impacts outlined below. As the scale of the changes in consumer expenditure (both in terms of reallocation and net increase) increase with more rapid deployment of technology and advanced powertrains (as these lead to larger shifts in fuel consumption, more purchases of vehicles with a lower TCO and require more infrastructure to support the larger fleet), the ELEC scenario shows the largest shifts in consumer expenditure in 2030, followed by FCV and BIO.

\subsection{Investment}

The deployment of PHEVs, BEVs and FCEVs all require the deployment of new infrastructure to allow the recharging/refuelling of these advanced powertrain vehicles. The VSM

Table 3: Consumer expenditure at market prices. Relative difference compared to baseline.

\begin{tabular}{lcc}
\hline Scenario & $\mathbf{2 0 3 0}$ & $\mathbf{2 0 5 0}$ \\
\hline BIO & $0.1 \%$ & $0.4 \%$ \\
ELEC & $1.0 \%$ & $1.0 \%$ \\
FCV & $1.0 \%$ & $1.2 \%$ \\
\hline
\end{tabular}


includes assumptions on the density of chargers required (including a distinction between, in the case of electric battery recharging, home, work and service station fast-recharging requirements) and the costs associated with the manufacture and installation of these. This requires additional investment (from either the public or private sector), which creates a short-term positive economic impact - however, given the rolling nature of the deployment of the infrastructure, this short-term impact perpetuates over the period to 2030 .

The scale of infrastructure required, and therefore the amount of investment required, is largest in scenarios where advanced powertrains represent the largest share of the vehicle stock. Investment over time, therefore, is driven by the time path of advanced powertrain penetration in the scenarios; earlier deployment in ELEC requires a developed charging infrastructure by 2030 , and by 2050 , additional investment is largely replacing existing charging infrastructure which has reached the end of its serviceable life. In the FCV scenario, there is some front-loading of infrastructure investment, but more investment is post-2030. As such, the investment impacts in 2030 are larger in the ELEC scenario, while by $2050 \mathrm{FCV}$ shows a larger increase above the baseline.

Investment is significantly smaller in the BIO scenario, where there is relatively low penetration of PHEVs and BEVs compared to the ELEC and FCV scenarios; relative to the baseline, only $0.1 \%$ of additional investment is required in 2050 .

In addition, all scenarios have small increases in investment due to the wider positive economic impacts; the increase in GDP (concentrated across the consumer services sectors) lead to small increases in investment from these sectors, reflecting the additional capital required to deliver the higher levels of output.

\subsection{Imports}

A shift to low-carbon fuels (biofuels, electricity and hydrogen created via electrolysis) will be a shift from fossil fuels, which are imported from overseas to fuels and electricity that are domestically produced. This has positive economic impacts, as expenditure which was previously being leaked overseas (to pay for imports) is, in the scenarios, being spent domestically, creating economic activity and jobs in the relevant fuel supply sectors and, through multiplier effects, activity in the supply chains to these sectors and the wider economy. However, as a counterpoint to this, vehicles with advanced powertrains require more expensive components, and the majority of these components are imported into Sweden. As such, there is an increase in the value of imports of motor vehicles and electrical equipment associated with the deployment of advanced powertrains. As such, although imports of manufactured fuels decrease, total imports see a net increase.

The shift in imports of fuels is driven by total demand for fossil fuels, which is a function of the deployment of fuel efficient technology and advanced powertrains. The largest decrease in manufactured fuel imports in 2030 is seen in the ELEC scenario, where substantial

Table 4: Investment. Relative difference compared to baseline.

\begin{tabular}{lcc}
\hline Scenario & $\mathbf{2 0 3 0}$ & $\mathbf{2 0 5 0}$ \\
\hline BIO & $0.0 \%$ & $0.1 \%$ \\
ELEC & $1.3 \%$ & $0.6 \%$ \\
FCV & $1.1 \%$ & $0.8 \%$ \\
\hline
\end{tabular}


decreases in demand from passenger cars and vans results in import of manufactured fuels being $4.9 \%$ lower in 2030 (although total imports are 1.0\% higher). In the FCV scenario, where the deployment of advanced powertrains takes place later (although it is then more wide ranging, including HGVs), imports of fuel fall by $4.8 \%$ in 2030 and $6.3 \%$ in 2050. Finally, in the BIO scenario, there is still a decrease in fossil fuel imports, due to the deployment of fuel efficient technology, but it is lower than in the other scenarios, at only $0.5 \%$ in 2030 (while total imports increase by $0.2 \%$ ).

Across most other products, imports increase in all scenarios; this result is driven by both the increased cost of components of advanced powertrain vehicles and the increased domestic economic activity, which increases demand for imports either as inputs to production or for final products for consumers. The largest increase in both 2030 and 2050 is seen in the FCV scenario, followed by the ELEC and BIO scenarios. This reflects the increased costs of FCV vehicles and components in the period to 2030, while by 2050 , despite falling technology costs, the larger increase in economic activity results in a larger increase in imports than in the ELEC scenario.

\subsection{Sensitivities}

During this modelling, a number of key assumptions have been made, and there is an element of uncertainty around each. As such, we have also tested the responsiveness of the results to variants of these key assumptions, in order to establish the extent to which our results (and specifically our conclusions) still hold under different possible futures.

From the analysis of the scenarios, the main economic impact of decarbonisation of transport in Sweden comes from the reduction in oil imports and the lowering fuel costs for motorists. This impact depends upon the relative prices of fuel over the period to 2030. In our baseline, the oil price projections used for this analysis are taken from IEA's November 2016 World Energy Outlook, and the cost of petrol and diesel production is assumed to grow in line with these oil prices over the period to 2050. However, in a world where transport is decarbonised not just in Sweden, but across other major oil consuming countries as well, the shift in demand could be large enough to cause a reduction in global oil prices. To assess the impact of this, we consider a world where oil prices fell by $30 \%$ over the period to 2030 .

Table 5: Imports. Relative difference compared to baseline.

\begin{tabular}{lcc}
\hline Scenario & $\mathbf{2 0 3 0}$ & $\mathbf{2 0 5 0}$ \\
\hline BIO & $0.2 \%$ & $0.7 \%$ \\
ELEC & $1.0 \%$ & $1.1 \%$ \\
FCV & $1.4 \%$ & $1.1 \%$ \\
\hline
\end{tabular}

Table 6: Imports of manufactured fuels. Relative difference compared to baseline.

\begin{tabular}{lcc}
\hline Scenario & $\mathbf{2 0 3 0}$ & $\mathbf{2 0 5 0}$ \\
\hline BIO & $-0.5 \%$ & $-1.6 \%$ \\
ELEC & $-4.9 \%$ & $-5.9 \%$ \\
FCV & $-4.8 \%$ & $-6.3 \%$ \\
\hline
\end{tabular}


In this sensitivity, although low oil prices reduced the relative benefits of the low-carbon transition in terms of GDP in the ELEC scenario in 2030 from $0.42 \%$ to $0.36 \%$, importantly the impacts were still positive. This is primarily because the efficiency savings of many technologies still lead to a net reduction in the total cost of owning a car, while the economic stimulus brought about by the investment in charging infrastructure is unaffected by the lower oil price. It should be noted that, because the deployment rates of technologies and powertrains is exogenous within the modelling, there is no change in take-up of these, which might reasonably be expected in a case where oil prices were lower (and therefore, the relative attractiveness of these technologies and powertrains was altered).

We also considered a high oil price sensitivity, which might occur if there is a disruption to global oil supplies. To model this, we modelled oil prices that increase to be $30 \%$ higher than the central case by 2030 . We find the relative benefits of decarbonising transport increase, due to a greater decrease in value of oil imports from decarbonisation. Furthermore, consumers see a larger fall in total cost of ownership from taking up new technologies and advanced powertrains, allowing the re-allocation of more consumer expenditure.

Given the switch towards the use of electricity as a fuel (or the use of electricity in generating hydrogen for use in fuel cells), the results are also heavily dependent upon the electricity price. Again, there is substantial uncertainty as to how electricity prices might develop out to 2030. If there is even more extensive decarbonisation of the power generation, prices could rise to pay for the deployment of additional electricity capacity (as electricity has to be generated from less optimal sites). Alternatively, technology improvements to grid storage may allow the share of renewables in the electricity mix to increase, leading to a fall in the marginal cost of electricity, which could have the effect of reducing prices considerably. To explore these sensitivities, we modelled a change in electricity prices of $\pm 30 \%$ by 2050 .

With higher electricity prices, there is a marginal reduction in the relative benefits of decarbonising transport. This is caused by a slight relative increase in the cost of ownership for motorists driving electric and fuel cell vehicles. With lower electricity, the relative reduction in cost of ownership leads to a modest change in consumption. Overall, however, the analysis is much less sensitive to changes in electricity prices as compared to changes in the oil price (there is a spread of less than $0.1 \%$ GDP for electricity prices and $0.6 \%$ for oil prices). The oil price effect is larger as the higher expenditure on oil in the scenarios is all exported (to the oil producing countries), whereas in the case of electricity, a higher price reflects higher revenues accrued elsewhere in the Swedish economy (for example by domestic construction firms installing the additional generation capacity) and therefore much of the value added is retained and recycled in the domestic economy through the multiplier effect.

\subsection{Discussion}

One of the major findings of the analysis is the role that biofuels must play in facilitating substantial reductions in emissions from the road transport system by 2030 . Fuel efficient technologies and advanced powertrains will serve to reduce the emissions from new vehicles incrementally as there are deployed, but these take time to permeate through the stock, as existing (more emissions-intensive) vehicles persist. Even aspirational deployments of technology and advanced powertrains will not reduce emissions sufficient to realise an $80 \%$ reduction in emissions in 2030 (as compared to 2010 levels), meaning that biofuels must play a role in meeting this. The advantage of the deployment of drop-in biofuels is that these impact upon the emissions of the entire vehicle stock, not just new vehicles. 
However, it is clear from this analysis that the deployment of drop-in biofuels is not a panacea to deliver Sweden's desired reductions in emissions. The potential volume of biomass that could be sustainably delivered in Sweden is around 12TWh in the short-term, rising to $18 \mathrm{TWh}$ in the long-term; and in our analysis, none of the technology deployments limited demand for biofuel in 2030 to less than the $12 \mathrm{TWh}$ capacity, with the additional requirements met through the import of biofuels in all cases. The discussion of the availability of biomass on a regional and global level, competition with food production, eco-resilience, etc. is outside the scope of this paper, but the assumptions we have made regarding availability are based on relatively conservative estimates that are valid for Sweden and primarily based on Swedish forestry and its residuals [11]. There is a limit to domestic biofuel production capacity, and our analysis suggests that, if Sweden is to meet this ambitious emissions reduction target, policy to support both the deployment of new technology and advanced powertrains and the drop-in biofuels is required.

It should be noted that there are some limitations to the analysis. The modelling framework does not include endogenous estimation of energy prices; as a result, prices of oil and/or electricity do not respond to changes in demand as might be expected. For example, the FCV scenario would require substantial amounts of electricity generation and, if this is based upon intermittent generation (e.g. wind, solar PV), very large amounts of capacity.

The levelized costs associated with this capacity are likely to be higher than the existing supply (as they are from higher up the cost-supply curve), and as such could be expected to increase average electricity prices. The impact of different oil and electricity prices is explored through sensitivities, but these are not varied between scenarios (in the sensitivity analysis a high electricity price in the BIO scenario is compared to high electricity prices in the CPI scenario, when it might be expected that the high electricity prices would only arise in the BIO scenario).

\section{CONCLUSIONS}

In this study we set out to close the knowledge gap regarding the macroeconomic consequences for Sweden to meet its $2030 \mathrm{CO}_{2}$ emissions target for road transport. We have achieved that by exploring potential pathways to meeting this target and compared them against each other and against a baseline scenario where only the currently known EU policies are met.

Sweden's $\mathrm{CO}_{2}$ emission target for road transport in 2030 can boost the Swedish economy, primarily as a result of the replacement of imported fossil fuels by domestically generated electricity and biofuels.

The 2030 target is only possible to reach through fossil $\mathrm{CO}_{2}$ emission reduction solutions that can work also on the stock of vehicles already on the market, because the addition of fuel efficiency technologies, and deployments of advanced powertrains, affects only new vehicle sales, and therefore over the limited time period between now and 2030 cannot have a sufficiently large impact on stock emissions. This therefore requires production of biofuels that are 'compatible' with existing petrol and diesel internal combustion engines, so called drop-in biofuels.

To reach the 2030 target, it is necessary to simultaneously implement new technologies, which improve the emissions intensity for internal combustion engines, as well as deploying advanced powertrains. A further reduction of fossil fuel demand through fuel cell technology and domestically produced hydrogen as fuel provides additional benefits in the long run (by 2050). The very ambitious 2030 target will also require imports of biofuels in the short term. 
This analysis shows that there is no time for hesitation if this emissions target is to be reached. An ambitious policy on drop-in fuels is needed, which requires an equally ambitious build-up of domestic biofuel production - or the full economic gains for Sweden will not materialise.

The need for a rapid increase of the share of electric vehicles and fuel cell vehicles in new vehicle sale will require strong and long-lasting policy instruments, for instance fiscal incentives for the purchase of advanced powertrains, to compensate for the early-stage differences in cost and attractiveness among offered technologies. Such policies can drive a quick shift towards electrification, at the same time as technology reduces the fuel use of the remaining ICEs that are sold and drop-in fuels reduce the emissions associated with ICE fuel consumption.

\section{ACKNOWLEDGEMENTS}

Funding for this project was provided by the Swedish Energy Agency and the European Climate Foundation.

\section{REFERENCES}

[1] Mundaca, L., Román, R. \& Cansino, J.M., Towards a green energy economy? a microeconomic-climate evaluation of Sweden's CO2 emissions. Applied Energy, 148, pp. 196-209, 2015. https://doi.org/10.1016/j.apenergy.2015.03.029

[2] Miljöutveckiling, Svenska Petroleum \& Biodrivmedel Institutet (SPBI), available at: http://spbi.se/miljoarbete/miljoutveckling/. (accessed 09 June 2017). (in Swedish). SPBI Branschfakta 2017; Svenska Petroleum \& Biodrivmedel Institutet (SPBI), available at: http://spbi.se/wp-content/themes/spi/resources/SPBI_branschfakta_2017.pdf. (accessed 09 June 2017). (in Swedish).

[3] Statens Offentliga Utredningar (SOU), En klimat- och luftvårdsstrategi för Sverige Del 1 SOU 2016:47, Elanders Sverige AB: Stockholm, 2016. (in Swedish).

[4] Statens Offentliga Utredningar (SOU), Fossilfrihet på väg Del 1 \& Del 2 SOU 2013:84, Elanders Sverige AB: Stockholm, 2013. (in Swedish).

[5] Fuelling Europe's Future, Cambridge Econometrics, available at: https://www.camecon.com/how/our-work/fuelling-europes-future/. (accessed 09 June 2017).

[6] Fuelling Britain's Future, Cambridge Econometrics, available at: https://www.camecon.com/how/our-work/fuelling-britains-future/.

[7] En route pour un transport durable, Cambridge Econometrics, available at: https:// www.camecon.com/how/our-work/en-route-pour-un-transport-durable/. (accessed 09 June 2017). (in French).

[8] E3ME Technical Manual, Version 6.0. April 2014, Cambridge Econometrics. available at: https://www.camecon.com/wp-content/uploads/2016/09/E3ME-Manual.pdf. (accessed 15 June 2017).

[9] Reducing $\mathrm{CO} 2$ emissions for passenger cars, European Commission, available at: https://ec.europa.eu/clima/policies/transport/vehicles/cars_en\#tab-0-0. (accessed 09 June 2017).

[10] Council Regulation (EC) No 2223/96 of 25 June 1996 on the European system of national and regional accounts in the Community, Council of the European Union, available at: http://publications.europa.eu/resource/cellar/1c8f3088-0209-4105-84382d29679a2c56.0008.02/DOC_1. (accessed 15 June 2017).

[11] Heyne, S., Grahn, M. \& Sprei, F., Systems perspectives on alternative future transportation fuels, Chalmers University of Technology, Göteborg, 2015. 